\title{
Structure, functional regulation and signaling properties of Rap2B (Review)
}

\author{
DEBAO QU ${ }^{1,2^{*}}$, HUI HUANG ${ }^{1 *}$, JIEHUI DI ${ }^{1,3}, \mathrm{KEYU} \mathrm{GAO}^{1}$, ZHENG LU $^{1}$ and JUNNIAN ZHENG ${ }^{1,3,4}$ \\ ${ }^{1}$ Cancer Institute, Xuzhou Medical College; ${ }^{2}$ Department of Radiotherapy, The Affiliated Hospital of Xuzhou Medical College; \\ ${ }^{3}$ Jiangsu Center for the Collaboration and Innovation of Cancer Biotherapy, Cancer Institute, Xuzhou Medical College; \\ ${ }^{4}$ Center of Clinical Oncology, The Affiliated Hospital of Xuzhou Medical College, Xuzhou, Jiangsu 221002, P.R. China
}

Received December 25, 2014; Accepted December 17, 2015

DOI 10.3892/ol.2016.4261

\begin{abstract}
The Ras family small guanosine 5'-triphosphate (GTP)-binding protein Rap2B is is a member of the Ras oncogene family and a novel target of p53 that regulates the p53-mediated pro-survival function of cells. The Rap2B protein shares $\sim 90 \%$ homology with Rap2A, and its sequence is $70 \%$ identical to other members of the Rap family such as RaplA and RaplB. As a result, Rap2B has been theorized to have similar signaling effectors to the GTPase-binding protein Rap, which mediates various biological functions, including the regulation of sterile 20/mitogen-activated proteins. Since its identification in the early 1990s, Rap2B has elicited a considerable interest. Numerous studies indicate that Rap2B exerts specific biological functions, including binding and stimulating phospholipase $\mathrm{C}-\varepsilon$ and interferon $-\gamma$. In addition, downregulation of Rap2B affects the growth of melanoma
\end{abstract}

Correspondence to: Professor Junnian Zheng, Jiangsu Center for the Collaboration and Innovation of Cancer Biotherapy, Cancer Institute, Xuzhou Medical College, 84 West Huai-Hai Road, Xuzhou, Jiangsu 221002, P.R. China

E-mail: jnzheng@xzmc.edu.cn

*Contributed equally

Abbreviations: cAMP, cyclic adenosine monophosphate; Epac, exchange protein directly activated by cAMP; GAP, GTPase-activating protein; GDP, guanosine diphosphate; GEF, guanine nucleotide exchange factor; GP, glycoprotein; GPCR, G protein-coupled receptor; GTP, guanosine 5'-triphosphate; JNK, c-Jun N-terminal kinase; MAP4K4, mitogen-activated protein kinase kinase kinase kinase 4; MINK, misshapen/NIK-related kinase; NCK, noncatalytic region of tyrosine kinase; $\mathrm{NF}-\kappa \mathrm{B}$, nuclear factor kappa-light-chain-enhancer of activated B cells; NIK, NF-кB-inducing kinase; PARG1, PTPL1-associated RhoGAP 1; PLC, phospholipase C; PI, phosphatidylinositol; PTPL1, protein tyrosine phosphatase-like protein 1 RA, Ras/Rap1A-associating; RhoGAP, Rho GTPase-activating protein; RPIP9, Rap2 interacting protein 9; SCC, squamous cell carcinoma; TNF, tumor necrosis factor; TNIK, TRAF2 and NCK-interacting kinase; TRAF2; TNF receptor-associated factor 2; vWF, von Willebrand factor

Key words: Rap2B, structure, effector, biological function, cancer cells. The present review summarizes the possible effectors and biological functions of Rap2B. Increasing evidence clearly supports the association between Rap2B function and tumor development. Therefore, it is conceivable that anticancer drugs targeting Rap2B may be generated as novel therapies against cancer.

\section{Contents}

1. Introduction

2. Identification and biological characteristics of Rap2B

3. Potential downstream effectors of Rap2B

4. Biological functions of Rap2B

5. Potential mechanism of Rap2B in tumor development

6. Conclusion

\section{Introduction}

The Ras family small guanosine 5'-triphosphate (GTP)-binding protein Rap2B is a member of the Ras oncogene family (1). Ras proteins are known to be promoters of tumorigenesis, and their expression has been observed in a variety of human tumors (2). In addition to the Rap family, Ras-related small GTPases include Ras, Rho, adenosine diphosphate (ADP) ribosylation factor, Ras-related nuclear protein and Rad, Rem, Rem2, Gem/Kir families (3-5). Ras is important in the regulation of cell growth and differentiation $(6,7)$. Furthermore, the Rap family presents $50-60 \%$ sequence homology with the product of the Ras proto-oncogene (8). Rap2A, Rap2B and Rap2C belong to the Rap2 subfamily (8). Rap2B protein shares $\sim 90 \%$ sequence homology with Rap2A, and $70 \%$ with RaplA and RaplB (9). In addition, RaplB and Rap2B are the only two members of the Rap family of GTPases that are expressed at significant levels in circulating human platelets (10-12). Additionally, Rap2B is geranylgeranylated, and associates with the membranes of human platelets and erythroleukemia cells $(13,14)$.

The present review focusses on the possible effectors and biological functions of Rap2B and summarizes current progress in the field. Since an increasing number of studies clearly supports the association between Rap2B and cancer, 
the present review discusses the potential role of Rap2B as a target for cancer therapy.

\section{Identification and biological characteristics of Rap2B}

Identification of Rap2B. In 1990, Rap2B was first identified when a platelet complementary (c)DNA library was screened $(10,15)$. Ohmstede et al (10) screened the platelet cDNA expression library with the anti-H-Ras monoclonal antibody M90, which is derived from human platelets. A specific epitope on the Ras-encoded p21 protein (amino acids, 107-130) was identified by the antibody, and an encoded partial amino acid sequence of a protein that was closely associated with Rap2 was identified by DNA sequence analysis of one clone (16). The authors revealed that this protein had $90 \%$ homology with Rap2 at the amino acid level, with variability at the carboxyl-terminus. The protein was named Rap2B. Although Rap2B is 90\% identical to Rap2 at the amino acid level with variability at the carboxyl-terminus, the expression and localization of different Rap2 family members remain tissue-specific for the different isoforms (10). Thus, Rap1B and Rap2B are present in the membrane of human platelets, while Rap2C localizes to the plasma membrane of eukaryotic cells (17). Additional studies have demonstrated that Rap2B is mainly expressed in human neutrophils, and the expression of Rap1B in platelets is $\sim 10$-fold higher than the expression of Rap2B (18). In addition, Torti and Lapetina (17) identified that the Rap2B protein, which is located at the cell membrane, was subjected to post-translational modifications, including isoprenylation, proteolysis and carboxymethylation. The characteristic intracellular localization of Rap2B suggests that it may exert a variety of cellular functions (19). Furthermore, an algorithm was developed to predict amino acid positions that may be exchanged to create switched functional mutants (20). The algorithm was validated by rendering switch-of-function mutants for Rap2B, which may be further investigated by combining genome-wide experimental functional classification (20).

Basic structural features of Rap2B. Since its identification in 1990, Rap2B has elicited a considerable interest $(1,10)$. The Rap2B gene, which has a conservative Rap domain, is located at the $3 \mathrm{q} 25.2$ region of the human chromosome (which has been extensively explored in previous studies on cancer), and has four expressed sequence tags $(21,22)$. The cDNA of the Rap2B gene is composed of an open reading frame of $552 \mathrm{bp}$, which shares $84.2 \%$ nucleotide and $89.6 \%$ amino acid homology with Rap2 (15). Using an integrative genomic approach, Zhang et al (1) identified Rap2B as a conserved p53-activated gene, which inhibited p53-mediated apoptosis following DNA damage. Upon DNA damage, p53 directly binds to the promoter of Rap2B and activates its transcription (1). Since the specificity of the gene determines the structure and function of the protein, the Rap2B protein is expected to exhibit a specific protein structure and function (23).

Rap2B encodes 183 amino acids, and is a Ras-related GTP-binding protein of low molecular weight (24). The structure of the Rap2B protein is similar to that of Ras proteins (8), and consists of an effector domain (amino acids, 32-40) that interacts with downstream effectors; nucleotide binding regions (amino acids, 11-148) that mediate the interaction between guanosine diphosphate (GDP) and GTP; and a carboxy-terminal CAAX motif (consisting of a cysteine followed by two aliphatic residues and one random amino acid) that targets proteins to the cell membrane (Fig. 1) $(5,25)$. All the proteins of the Rap2 family present a cysteine residue (C180) downstream of the cysteines C176 and C177 in the CAAX motif (26). A previous study demonstrated that palmitoylation occurs at the $\mathrm{C} 176 / 177$ sites, which requires CAAX processing (27). The C-terminus is also the site of sequential post-translational modifications (26). Despite the fact that the open reading frame of Rap2B shares $84.2 \%$ nucleotide and $89.6 \%$ amino acid homology with Rap2, its C-terminal region is different (15). The Rap2B clone contains the amino acid sequence CVIL, whereas Rap2 terminates with CNIQ (15). In addition, the insertion of a polyisoprenic tail in the cysteine residue of the CAAX motif has been demonstrated to be involved in post-translational modifications (14).

Regulation of Rap $2 B$ activity. The regulation of Rap2B as a molecular switch of signaling pathways is determined by its association with GDP ('off' position) or GTP ('on' position) (28). Similarly to other GTPases that serve as molecular switches by cycling between GTP-bound active and GDP-bound inactive forms (5), the Rap2B protein is considered to be active when is associated with GTP, and inactive when is associated with GDP (29). Therefore, the Rap2B protein functions as a binary switch by cycling between two interconvertible states: A GDP-bound inactive and a GTP-bound active form (28). A previous study comparing the kinetics of nucleotide binding and release revealed that Rap2B bound GTP more efficiently and possessed a faster rate of GDP release than its highly homologous Rap2C (8). Furthermore, in the presence of magnesium $\left(\mathrm{Mg}^{2+}\right)$, the relative affinity of Rap2B for GTP was $\sim 7$-fold higher than its affinity for GDP (30). However, under the same conditions, the relative affinity of Rap2C for GTP was only 2 -fold higher, compared with its affinity for GDP (8). In addition, the binding of GTP to Rap2B was stronger and more rapid in the absence of $\mathrm{Mg}^{2+}$ (30). Although the specific reason was unclear, the present review hypothesizes that this may be due to the concurrence of various intrinsic properties of this protein (19). Rap2B encodes intrinsic GTPase enzymatic activity, and the function of Rap2B is regulated by guanine nucleotide exchange factors (GEFs) and GTPase-activating proteins (GAPs). The rapid and sustained binding of GTP to Rap2B has been previously observed to be induced by thrombin, which stimulates heterotrimeric $\mathrm{G}$ protein-coupled receptors (GPCRs), and the glycoprotein (GP) VI ligand convulxin, which activates a tyrosine kinase-based signaling pathway (18). Thrombin- and convulxin-induced activation of Rap2B were not observed to be dependent on thromboxane A2 (18). However, intracellular calcium $\left(\mathrm{Ca}^{2+}\right)$ was observed to be capable of regulating the activation of Rap2B. Furthermore, Rap2B activation induced by thrombin was required for phosphatidylinositol (PI) 3-kinase activity (18). In addition, Rap2B is also activated by the GEF exchange protein directly activated by cyclic adenosine monophosphate (cAMP) (Epac), which is regulated by cAMP (30-35).

Regulators of Rap2B activity. The process of cycling between GTP and GDP is facilitated by cytosolic factors and 


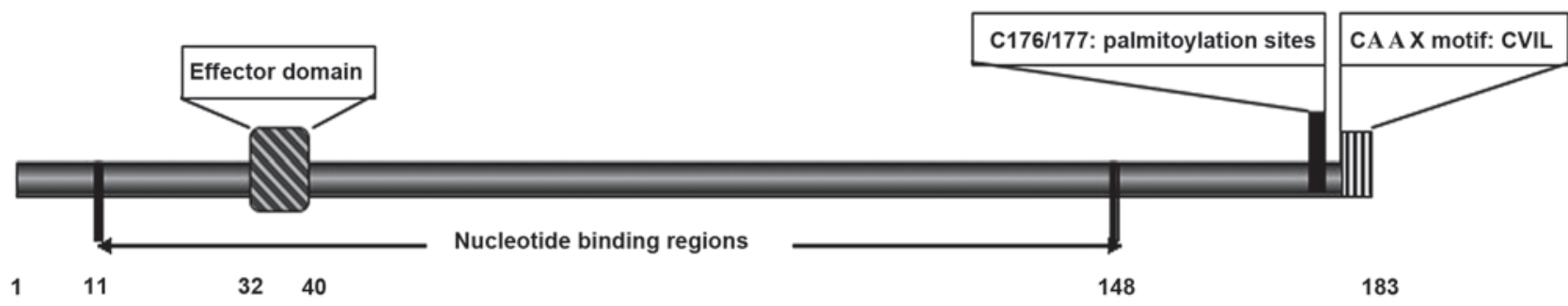

Figure 1. Domain structure of Rap2B, a Ras family small guanosine 5'-triphosphate-binding protein. Rap2B is composed of an effector domain (amino acids, 32-40), nucleotide binding regions (amino acids, 11-148) and a carboxy-terminal CAAX motif (amino acids, 179-183). The CAAX motif consists of a cysteine followed by two aliphatic residues and one random amino acid. Rap2B terminates with a CVIL motif. C176/C177 are the palmitoylation sites of Rap2B.

generally induced by GEFs (36). Inactivation occurs through the intrinsic GTPase activity of Rap2B, which converts bound GTP into GDP, and is stimulated by GAPs (28). Furthermore, in small GTP-binding proteins, GAPs enhance the intrinsic GTPase activity to hydrolyze GTP to GDP, whereas GEFs promote the release of bound GDP and the capture of a new GTP molecule (25). Rap2B and Rap have similar activation and deactivation regulatory factors, including several GEFs and GAPs, which are capable of regulating the activity of Rap proteins (37). GEFs that regulate the activity of Rap2B include C3G (a GEF bound to the adaptor protein c-Crk), Epac, Ras guanyl-releasing protein (GRP) 2 and Ras/Rap1A-associating (RA)-GEF-1, while Rap GAPs include Rap1GAPII and suppressor of phyA-105 1 (38-40).

\section{Potential downstream effectors of Rap2B}

Rap2B belongs to the Rap2 family of small GTP-binding proteins, and shares $90 \%$ sequence homology with Rap2 at the amino acid level, with marked variability at the carboxyl-terminus (10). Although specific downstream effectors of Rap2B are unknown, it may be hypothesized that specific effectors of Rap2B are similar to those of Rap2. There are various specific effectors of Rap2, including mitogen-activated protein kinase kinase kinase kinase 4 (MAP4K4), misshapen/nuclear factor kappa-light-chain-enhancer of activated $\mathrm{B}$ cells $(\mathrm{NF}-\kappa \mathrm{B})$-inducing kinase-related kinase (MINK), tumor necrosis factor receptor-associated factor 2 and noncatalytic region of tyrosine kinase-interacting kinase (TNIK), protein tyrosine phosphatase-like protein 1-associated RhoGAP 1 (PARG1) and Rap2 interacting protein 9 (RPIP9) (41-43). These Rap2 specific effectors interact with Rap2 through the C-terminal Citron homology domain (44).

MAP4K4 (also termed hepatocyte progenitor kinase-like/germinal center kinase-like kinase), MINK and TNIK belong to the human sterile 20 (STE20)/MAP4K family (45). MAP4K4 has been demonstrated to be highly expressed in the majority of tumor cell lines. Machida et al (44) revealed that MAP4K4 regulates c-Jun N-terminal kinase (JNK), and observed that MAP4K4-induced activation of JNK was enhanced by Rap2. Collins et al (46) demonstrated that the effects of MAP4K4 on promoting cellular migration were mediated through JNK, independently of activator protein 1 (AP-1) activation and downstream transcription. MINK is highly expressed in the brain, and its interaction with Rap2 is GTP-dependent and requires the presence of phenylalanine at position 39 within the effector region of Rap2 (43). TNIK was observed to be activated by the palmitoylation-deficient mutant of mouse Rap2B, and Rap2B promoted the growth and development of tumor cells through the activation and interaction with TNIK (42). Furthermore, Rap2B does not induce a TNIK-mediated cellular phenotype, but TNIK activation requires palmitoylation-independent membrane-association of Rap2B (47). In addition, all Rap2 proteins, including Rap2B, require palmitoylation for the induction of the TNIK-mediated phenotype, which led to the suppression of proliferation of human embryonic kidney (HEK)293T cells in a previous study (47). Nonaka et al (43) confirmed that MINK and TNIK interact with a postsynaptic scaffold protein containing tetratricopeptide repeats, ankyrin repeats and a coiled-coil region, inducing its phosphorylation, which is enhanced by Rap2.

PARG1 is a putative specific effector of Rap2 that regulates Rho and exhibits RhoGAP activity in vitro (25). PARG1 and ZK669.1a, a protein that contains a RhoGAP domain, share a homology region, and the Caenorhabditis elegans ortholog of Rap2 has been demonstrated to interact with ZK669.1a (25). Rap2 suppresses the PARG1-induced cytoskeletal alterations required for Rho inactivation in vivo (25).

RPIP9 is coded by the multidrug resistance protein 1 gene, which is upregulated in numerous tumors, and overlaps with a non-characterized gene transcribed from the opposite strand (48). The predicted protein exhibits high homology to human RPIP8, and has a RUN domain located near its C-terminus (49). The activation of RPIP9 occurs during malignant breast epithelial transformation, and its expression increases with the progression of cancer toward an invasive phenotype (48). However, the role of Rap2 in breast cancer remains unknown. The specific downstream effector of Rap2B is unclear. However, the open reading frame of Rap2B shares $84.2 \%$ nucleotide and $89.6 \%$ amino acid homology with Rap2. Therefore, the present study hypothesizes that Rap2B regulates a variety of signaling pathways by interacting with MAP4K4, MINK, TNIK, PARG1 and RPIP9 (Fig. 2).

\section{Biological functions of Rap2B}

Acting as molecular switches, small GTPases are able to regulate several cellular processes, including adhesion, proliferation, differentiation and apoptosis (27). In the Ras subfamily, the interaction of the Ras family members depends 
A

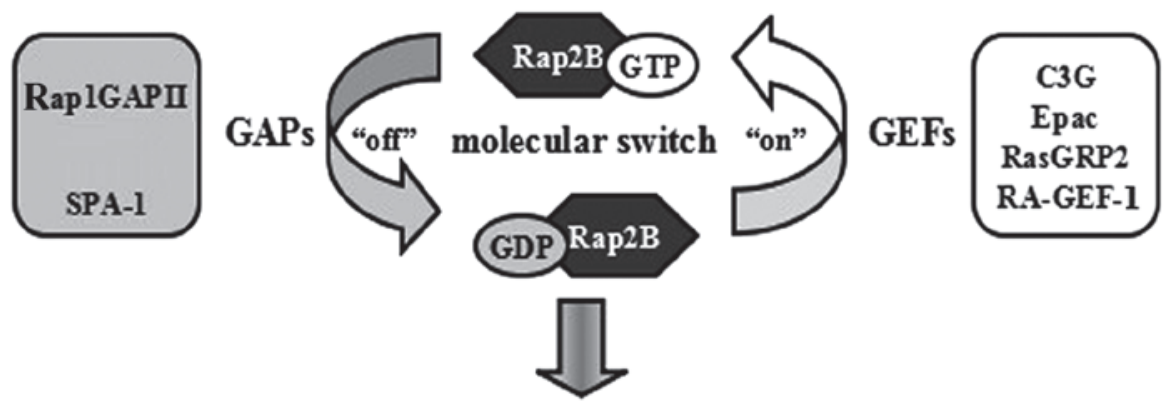

B

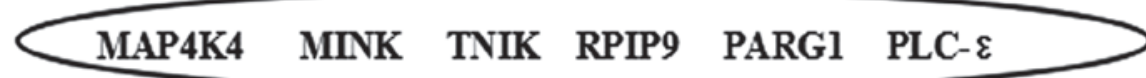

C

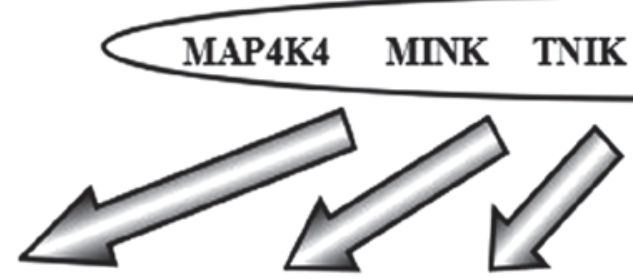

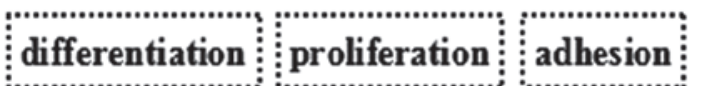

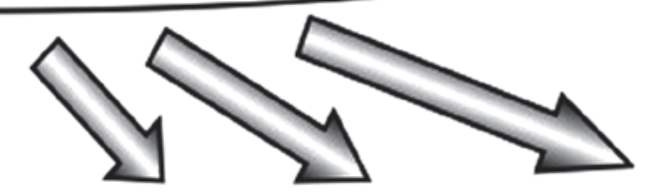

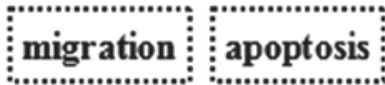

cancer development

Figure 2. Signaling pathway and biological function of Rap2B, a Ras family small guanosine 5'-triphosphate-binding protein. (A) Rap2B functions as a binary switch. (B) Specific effectors of Rap2B. (C) Rap2B regulates various cellular biological functions by interacting with specific effectors. GAP, GTPase-activating protein; SPA-1, suppressor of phyA-105 1; GTP, guanosine 5'-triphosphate; GDP, guanosine diphosphate; GEF, guanine nucleotide exchange factor; Epac, exchange protein directly activated by cyclic adenosine monophosphate; GRP, guanyl-releasing protein; RA, Ras/Rap1A-associating; MAP4K4, mitogen-activated protein kinase kinase kinase kinase 4; MINK, misshapen/NIK-related kinase; NIK, NF- $\kappa$ B-inducing kinase; NF- $\mathrm{B}$, nuclear factor kappa-light-chain-enhancer of activated B cells; TNIK, TRAF2 and NCK-interacting kinase; TRAF2; TNF receptor-associated factor 2; TNF, tumor necrosis factor; NCK, noncatalytic region of tyrosine kinase; RPIP9, Rap2 interacting protein 9; PARG1, PTPL1-associated RhoGAP 1; PLC, phospholipase C.

on the potential for interactions (which is dictated by their structure), the subcellular localization of the particular protein and its potential regulators and effectors (50). The affinities of the different Ras members for their regulators or effectors and their precise subcellular localization results in various biological functions (51).

Rap2B, as a novel p53 target, regulates the p53-mediated pro-survival function. The tumor suppressor p53 is a DNA sequence-specific transcription factor and a stress sensor (52-54). Zhang et al (1) identified Rap2B as a novel p53 target that mediates cell survival following DNA damage. Consistent with its pro-survival function, the authors also revealed via analysis of cancer genomic data that Rap2B is overexpressed in numerous types of tumors. Rap2B exhibits weak transforming activity, which was observed using anchorage-independent growth assays, suggesting that Rap2B is not an oncogene by itself (1). This also suggests that targeting Rap2B may sensitize tumor cells to apoptosis induced by DNA damage (1). Unpublished data by the authors of the present study also confirmed that Rap2B is the direct target gene of $\mathrm{p} 53$, and has a p53-dependent pro-survival function.

Translocation of Rap1B and Rap2B to the cytoskeleton via von Willebrand factor ( $v W F$ ) involves Fcy receptor II (FcyRII)-mediated protein tyrosine phosphorylation. Rap1B and Rap2B are the only members of the Rap family of GTPases that are expressed at significant levels in circulating human platelets $(8,17)$. Notably, Rap1B is $\geq 10$ times more abundant than Rap2B in platelets (17). Previous kinetic studies demonstrated that the translocation of Rap1B to the cytoskeleton preceded the translocation of Rap2B, which only occurs in the late phase of platelet aggregation in thrombin-stimulated platelets $(55,56)$. Greco et al (18) revealed that the activation of Rap2B may be stimulated by thrombin or convulxin in platelets. However, the specific mechanisms of translocation of Rap1B and Rap2B to the cytoskeleton remain unclear. The large GP vWF is synthesized by megakaryocytes and endothelial cells, and is important in thrombus formation and platelet adhesion (57). In platelets, the GPIb-IX-V complex, a member of the leucine-rich GP gene family, is the main receptor for vWF (58). In 1999, Torti et al (59) revealed that the translocation of Rap1B and Rap2B to the cytoskeleton was induced by vWF, following binding of vWF to the GPIb-IX-V complex through a GP IIb/IIIa-independent mechanism. In a previous study, Rap2B was prevented from associating with the cytoskeleton by cytochalasin $\mathrm{D}$, which did not inhibit platelet aggregation (60). These results provide a novel role for $\mathrm{Fc} \gamma \mathrm{RII}$ in regulating the translocation of Rap proteins to the cytoskeleton and mediating protein tyrosine phosphorylation.

Targeting of Rap2B to lipid rafts is promoted by palmitoylation at $C 176$ and $C 177$, and is required for efficient protein activation in blood platelets. Lipid rafts are dynamic membrane microdomains abundant in cholesterol and glycosphingolipids (61), which appear to be important for human platelet activation $(62,63)$ and are also implicated in signal transduction. Furthermore, there are specific differences in the mechanisms for agonist-induced activation of Rap1B and Rap2B, particularly in their dependence on secreted ADP in human platelets (18). Previous studies have observed that the thrombin-induced activation of Rap2B was significantly reduced when secreted ADP was neutralized (64). In 2008, Canobbio et al (27) observed that $20 \%$ 
of all the membrane-bound Rap2B protein localizes to the membrane microdomain lipid rafts, while the majority of membrane-associated Rap2B is outside these microdomains. The authors also revealed that the association of Rap2B to lipid rafts is promoted by palmitoylation of C176 and C177, which are located at the $\mathrm{C}$-terminal region of the protein. These residues are required for the complete activation of Rap2B, and are induced by stimulation of human platelets (27). Although additional studies are required to fully elucidate the biochemical and functional characterization of Rap2B in platelets, the above previous results indicate a novel biochemical property of Rap2B, and demonstrate the important role of $\mathrm{Rap} 2 \mathrm{~B}$ in regulating the activation and aggregation of blood platelets.

Rap2B interacts with phospholipase C (PLC)-E and activates $i t$. Inositol-specific mammalian PLC enzymes are multidomain proteins whose functions are regulated by $\mathrm{G}$ proteins (65). Heterotrimeric $\mathrm{G}$ proteins and Ras-like GTPases directly activate the isozymes of PLC (66). In a wide variety of membrane receptors, the hydrolysis of PI 4,5-bisphosphate via stimulation of phosphoinositide-specific PLC, and the subsequent generation of inositol 1,4,5-trisphosphate, is used as the main $\mathrm{Ca}^{2+}$ signaling pathway (67). In 2001, Schmidt et al (68) identified a novel PLC and $\mathrm{Ca}^{2+}$ signaling pathway that was mediated by a small GTPase of the Rap family, and was triggered by cAMP. The authors also provided evidence that these receptor responses, mediated by Rap2B, activated Epac, which was regulated by cAMP $(31,32)$, and involved the PLC- $\varepsilon$ isoform (33-25). PLC- $\varepsilon$ is a novel PLC that possesses a cell division cycle 25 GEF domain and two Ras-associating domains, of which RA2 is critical for Ras-mediated activation of the enzyme (69,70). In 2003, Wing et al (71) reported that PLC- $\varepsilon$ senses and mediates the crosstalk between heterotrimeric and small GTPase signaling pathways, acting as a multifunctional nexus protein. Additional studies indicated that PLC- $\varepsilon$ is important in promoting bladder cell transitional proliferation, and small GTPases of the Ras and Rho families have been observed to control the activity of PLC- $\varepsilon$ (72-74). The findings from the study by Lopez et al (33) demonstrate that PLC- $\varepsilon$ is regulated by the heterotrimeric $\mathrm{G}$ protein $\mathrm{G} \alpha$, and activates the small $\mathrm{G}$ protein Ras/mitogen-activated protein kinase (MAPK) signaling pathway. Stope et al (75) suggested that epidermal growth factor receptor triggers the activation of Rap2B via PLC $\alpha 1$ activation and tyrosine phosphorylation of the GEF RasGRP3 by the proto-oncogene tyrosine-protein kinase c-Src, which results in the stimulation of PLC- $\varepsilon$. In 2002, Evellin et al (76) demonstrated that PLC- $\varepsilon$ appeared to be stimulated by GPCRs through the formation of cAMP and activation of Rap2B. Rap2B may promote cell adhesion, spread, migration and polarity, in addition to integrin activation, axonal outgrowth and phagocytosis, through interacting with R-Ras effectors such as PLC- $\varepsilon$ (76-83).

In addition, a diverse array of cellular functions are coordinated by interferon (IFN) $-\gamma$ through the transcriptional regulation of immunologically relevant genes (84). In 2005 , Gollob et al (85) revealed that the growth of melanoma cells was affected by IFN- $\gamma$, and the anti-melanoma effect of IFN- $\gamma$ in the human melanoma DM6 cell line was associated with the downregulation of multiple genes involved in $G$ protein signaling and PLC activation, including Rap2B and calpain 3, using DNA microarray analysis. Therefore, the data provided novel insights into the signaling events and gene expression alterations associated with the growth inhibition and apoptosis of melanoma cells, which may result in the identification of novel targets for melanoma therapy (86). In summary, following activation by heterotrimeric $\mathrm{G}$ protein signaling, Rap2B interacts with PLC- $\varepsilon$, activating it, which affects cell growth by activating the Ras-Raf-MAPK/extracellular signal-regulated kinase (ERK) signaling pathway (71).

Rap2B is a novel candidate gene cloned from lung cancer cells. Rap2B is one of the 50 novel candidate genes cloned from differential expression cDNA libraries constructed in lung cancer cells (87). In 2007, Liu et al (88) used the suppression subtractive hybridization method to identify differentially expressed genes in lung squamous cell carcinoma (SCC). The results revealed that the messenger RNA and protein expression levels of Rap2B in lung cancer tissues was increased, compared with normal tissues. A reporter gene assay demonstrated that Rap2B activated the NF- $\kappa$ B pathway $>3$-fold, compared with the mock vector (87). Although the specific mechanism remains unclear, this observation implied that Rap2B may play a potential role in the development and progression of lung SCC.

\section{Potential mechanism of Rap2B in tumor development}

Similarly to other Ras proteins, Rap2B is associated with the occurrence and development of tumors $(1,87)$. Certain studies have reported an association between the function of Rap2B and the development of malignant tumors, and increasing evidence clearly confirms this association $(1,87)$. Although the mechanism of Rap2B in cancer is not clear, the function of Rap2B relies on its gene homology and protein structure (23). Therefore, it may be hypothesized that Rap2B is involved in tumor development.

The formation of tumors results from abnormal proliferation of normal cells, which usually present as abnormal masses in the body (89). Numerous studies have observed that the occurrence and development of cancer are complex processes that are regulated by multiple genes and factors (90). The abnormal activation of oncogenes and inactivation of tumor suppressor genes serve as a major contribution to tumor development (91). The open reading frame of Rap2B shares $84.2 \%$ nucleotide and $89.6 \%$ amino acid homology with Rap2 (15). Therefore, Rap2B may regulate a variety of signaling pathways, in addition to cell spreading through its interaction with MAP4K4, MINK, TNIK, PARG1 and RPIP9 $(92,93)$. By contrast, PLC- $\varepsilon$, which is activated by and interacts with Rap2B, facilitates cell growth through activating the Ras-Raf-MAPK/ERK pathway, which increases intracellular $\mathrm{Ca}^{+2}$ levels and activates protein kinase C (75). Therefore, Rap2B may promote the development of tumors through its interaction with PLC- $\varepsilon$. In addition, it has been observed that ERK activation by $\beta 2$-adrenergic receptor and prostaglandin E1 receptor in HEK293T cells and mouse neuroblastoma N1E-115 cells, respectively, is mediated by cAMP-activated Epac proteins, which leads to an increase in the intracellular levels of $\mathrm{Ca}^{+2}$ via Rap2B and PLC- $\varepsilon$ stimulation $(38,94)$. This results in the activation of $\mathrm{H}-\mathrm{Ras}$, which 
triggers the MAPK cascade (38), and may also regulate the interaction between PLC- $\varepsilon$ and Rap2B.

In vivo, the number and volume of Ras-induced tumor nodules is increased significantly by JNK deficiency, and the oncogenic effects of Ras are suppressed by the JNK signaling pathway (95). Growth arrest and apoptosis of certain tumor cells is caused by inhibition of JNK (96-98). Phosphorylation of c-Jun and increase of AP-1 transcriptional activity may be a result of activating Rap2B by the JNK/MAPK signaling cascade (80). This interaction between JNK and Rap2B is also a possible mechanism that explains tumor development.

Autophagy is considered a cell survival mechanism, which is activated in response to various stress signals, including high temperature, oxidative stress and accumulation of damaged organelles (99). The pathogenesis of clinically important disorders in a variety of organ systems contribute to the dysregulation of autophagy (100). Staphylococcus aureus is a pathogen that colonizes the lungs of patients with cystic fibrosis (101) and causes serious infectious diseases (102). In 2012, Mestre and Colombo (103) demonstrated that S. aureus induces an autophagic response to promote bacterial growth. The authors also revealed that $S$. aureus-induced autophagy may be regulated by RapGEF3 and Rap2B through calpain activation, and activated RapGEF3 and Rap2B may prevent the action of $S$. aureus by decreasing intracellular cAMP levels. Therefore, Rap2B may regulate the autophagy and survival of S. aureus to affect tumor development.

In 2004, McLeod et al (104) provided evidence for the regulation of integrins by Rap2B in B cells. The authors described that cell adhesion and spreading, in addition to actin polymerization and integrin-mediated Pyk2 tyrosine phosphorylation, are regulated by Rap GTPases in B cells. Consequently, the present review hypothesizes that Rap2B may regulate the immune system by promoting tumorigenesis. Although certain biochemical and functional roles of Rap2B have been elucidated, additional studies are required to fully understand the functional mechanism of Rap2B and its association with tumor development.

\section{Conclusion}

Previous studies have suggested that targeting Rap2B may sensitize tumor cells to undergo apoptosis in response to DNA damage, since Rap2B is a conserved p53-activated gene (1). However, anticancer drugs that target Rap2B remain a theory, since an improved understanding at a molecular level of exactly how Rap2B functions as a tumor promoter is required prior to the development of novel drugs targeting Rap2B. Therefore, the identification of the functions of Rap2B may result in novel avenues of research aimed to improve therapeutics and prognosis of human malignancies.

Inhibiting the expression of Rap2B may potentially be useful in cancer therapy, and has gained attention in the treatment of various types of cancer that display increased expression of Rap2B proteins (105). This may offer novel therapeutic strategies for the treatment of human carcinoma, and may eventually lead to the development of a novel class of anticancer drugs that target Rap2B, and promote the development of sensitive biomarkers for cancer diagnosis and treatment. Future studies on Rap2B will provide evidence and generate mechanistic hypotheses regarding the development of cancer. Identifying and understanding the functionally important Ras family of proteins may clarify the biology of cancer and lead to novel therapeutic and diagnostic opportunities for patients affected by this disease.

\section{Acknowledgements}

The present study was supported by the National Natural Science Foundation of China (Beijing, China; grant nos. 81272207 and 81201637) and Natural Science Foundation for Colleges and Universities in the Jiangsu Province (Beijing, China; grant no. 14KJB320023). Miss Jiehui Di was sponsored by the Qing Lan Project of Jiangsu Province (Nanjing, China).

\section{References}

1. Zhang X, He Y, Lee KH, Dubois W, Li Z, Wu X, Kovalchuk A, Zhang $\mathrm{W}$ and Huang J: Rap2b, a novel p53 target, regulates p53-mediated pro-survival function. Cell cycle 12: 1279-1291, 2013.

2. Takashima A and Faller DV: Targeting the RAS oncogene. Expert Opin Ther Targets 17: 507-531, 2013.

3. Mackay DJ and Hall A: Rho GTPases. J Biol Chem 273: 20685-20688, 1998.

4. Vojtek $A B$ and Der CJ: Increasing complexity of the Ras signaling pathway. J Biol Chem 273: 19925-19928, 1998.

5. Takai Y, Sasaki T and Matozaki T: Small GTP-binding proteins. Physiol Rev 81: 153-208, 2001.

6. Bourne HR, Sanders DA and McCormick F: The GTPase superfamily: A conserved switch for diverse cell functions. Nature 348: 125-132, 1990.

7. Bourne HR, Sanders DA and McCormick F: The GTPase superfamily: Conserved structure and molecular mechanism. Nature 349: 117-127, 1991.

8. Paganini S, Guidetti GF, Catricalà $S$, Trionfini $P$, Panelli $S$, Balduini $\mathrm{C}$ and Torti $\mathrm{M}$ : Identification and biochemical characterization of Rap2C, a new member of the Rap family of small GTP-binding proteins. Biochimie 88: 285-295, 2006.

9. Greco F, Ciana A, Pietra D, Balduini C, Minetti G and Torti M: Rap2, but not Rap1 GTPase is expressed in human red blood cells and is involved in vesiculation. Biochim Biophys Acta 1763: 330-335, 2006

10. Ohmstede CA, Farrell FX, Reep BR, Clemetson KJ and Lapetina EG: RAP2B: A RAS-related GTP-binding protein from platelets. Proc Natl Acad Sci USA 87: 6527-6531, 1990.

11. Lapetina EG, Lacal JC, Reep BR and Molina y Vedia L: A ras-related protein is phosphorylated and translocated by agonists that increase cAMP levels in human platelets. Proc Natl Acad Sci USA 86: 3131-3134, 1989.

12. Klinz FJ, Seifert R, Schwaner I, Gausepohl H, Frank R and Schultz G: Generation of specific antibodies against the rap1A, rap1B and rap2 small GTP-binding proteins. Analysis of rap and ras proteins in membranes from mammalian cells. Eur J Biochem 207: 207-213, 1992.

13. Winegar DA, Molina y Vedia L and Lapetina EG: Isoprenylation of rap2 proteins in platelets and human erythroleukemia cells. J Biol Chem 266: 4381-4386, 1991.

14. Farrell FX, Yamamoto K and Lapetina EG: Prenyl group identification of rap2 proteins: A ras superfamily member other than ras that is farnesylated. Biochem J 289: 349-355, 1993.

15. Farrell FX, Ohmstede CA, Reep BR and Lapetina EG: cDNA sequence of a new ras-related gene (rap2b) isolated from human platelets with sequence homology to rap2. Nucleic Acids Res 18: $4281,1990$.

16. Lerosey I, Chardin P, de Gunzburg J and Tavitian A: The product of the rap2 gene, member of the ras superfamily. Biochemical characterization and site-directed mutagenesis. J Biol Chem 266: 4315-4321, 1991.

17. Torti M and Lapetina EG: Structure and function of rap proteins in human platelets. Thromb Haemost 71: 533-543, 1994.

18. Greco F, Sinigaglia F, Balduini C and Torti M: Activation of the small GTPase Rap2B in agonist-stimulated human platelets. J Thromb Haemost 2: 2223-2230, 2004. 
19. Chen J, Liang H and Fernández A: Protein structure protection commits gene expression patterns. Genome Biol 9: R107, 2008.

20. Heo WD and Meyer T: Switch-of-function mutants based on morphology classification of Ras superfamily small GTPases. Cell 113: 315-328, 2003

21. Sun W, Zhang K, Zhang X, Lei W, Xiao T, Ma J, Guo S, Shao S, Zhang H, Liu Y, et al: Identification of differentially expressed genes in human lung squamous cell carcinoma using suppression subtractive hybridization. Cancer Lett 212: 83-93, 2004.

22. An Q, Pacyna-Gengelbach M, Schlüns K, Deutschmann N, Guo S, Gao Y, Zhang J, Cheng S and Petersen I: Identification of differentially expressed genes in immortalized human bronchial epithelial cell line as a model for in vitro study of lung carcinogenesis. Int J Cancer 103: 194-204, 2003.

23. Schlicker A, Domingues FS, Rahnenführer J and Lengauer T: A new measure for functional similarity of gene products based on Gene Ontology. BMC Bioinformatics 7: 302, 2006.

24. Colicelli J: Human RAS superfamily proteins and related GTPases. Sci STKE 2004: RE13, 2004.

25. Myagmar BE, Umikawa M, Asato T, Taira K, Oshiro M, Hino A, Takei K, Uezato $\mathrm{H}$ and Kariya K: PARG1, a protein-tyrosine phosphatase-associated RhoGAP, as a putative Rap2 effector. Biochem Biophys Res Commun 329: 1046-1052, 2005.

26. Taguchi $\mathrm{T}$ and Misaki R: Palmitoylation pilots ras to recycling endosomes. Small GTPases 2: 82-84, 2011.

27. Canobbio I, Trionfini P, Guidetti GF, Balduini C and Torti M Targeting of the small GTPase Rap2b, but not Rap1b, to lipid rafts is promoted by palmitoylation at Cys176 and Cys177 and is required for efficient protein activation in human platelets. Cell Signal 20: 1662-1670, 2008.

28. Raaijmakers JH and Bos JL: Specificity in Ras and Rap signaling. J Biol Chem 284: 10995-10999, 2009.

29. Hattori M and Minato N: Rap1 GTPase: Functions, regulation, and malignancy. J Biochem 134: 479-484, 2003.

30. Molina y Vedia L, Ohmstede CA and Lapetina EG: Properties of the exchange rate of guanine nucleotides to the novel rap-2B protein. Biochem Biophys Res Commun 171: 319-324, 1990.

31. de Rooij J, Zwartkruis FJ, Verheijen MH, Cool RH, Nijman SM, Wittinghofer A and Bos JL: Epac is a Rap1 guanine-nucleotide-exchange factor directly activated by cyclic AMP. Nature 396: 474-477, 1998.

32. de Rooij J, Rehmann H, van Triest M, Cool RH, Wittinghofer A and Bos JL: Mechanism of regulation of the Epac family of cAMP-dependent RapGEFs. J Biol Chem 275: 20829-20836, 2000

33. Lopez I, Mak EC, Ding J, Hamm HE and Lomasney JW: A novel bifunctional phospholipase $\mathrm{c}$ that is regulated by Galpha 12 and stimulates the Ras/mitogen-activated protein kinase pathway. J Biol Chem 276: 2758-2765, 2001

34. Kelley GG, Reks SE, Ondrako JM and Smrcka AV: Phospholipase C(epsilon): A novel Ras effector. EMBO J 20: 743-754, 2001

35. Song C, Hu CD, Masago M, Kariyai K, Yamawaki-Kataoka Y, Shibatohge M, Wu D, Satoh T and Kataoka T: Regulation of a novel human phospholipase C, PLCepsilon, through membrane targeting by Ras. J Biol Chem 276: 2752-2757, 2001

36. Cherfils J and Chardin P: GEFs: Structural basis for their activation of small GTP-binding proteins. Trends Biochem Sci 24: 306-311, 1999

37. Stork PJ: Does Rap1 deserve a bad Rap? Trends Biochem Sci 28: 267-275, 2003

38. Keiper M, Stope MB, Szatkowski D, Böhm A, Tysack K Vom Dorp F, Saur O, Oude Weernink PA, Evellin S, Jakobs KH and Schmidt M: Epac- and $\mathrm{Ca}^{2+}$-controlled activation of Ras and extracellular signal-regulated kinases by Gs-coupled receptors. J Biol Chem 279: 46497-46508, 2004.

39. Rebhun JF, Castro AF and Quilliam LA: Identification of guanine nucleotide exchange factors (GEFs) for the Rap1 GTPase. Regulation of MR-GEF by M-Ras-GTP interaction. J Biol Chem 275: 34901-34908, 2000

40. Gasper R, Sot B and Wittinghofer A: GTPase activity of Di-Ras proteins is stimulated by Rap1GAP proteins. Small GTPases 1: 133-141, 2010.

41. Ryu J, Futai K, Feliu M, Weinberg R and Sheng M: Constitutively active Rap2 transgenic mice display fewer dendritic spines, reduced extracellular signal-regulated kinase signaling, enhanced long-term depression, and impaired spatial learning and fear extinction. J Neurosci 28: 8178-8188, 2008.

42. Taira K, Umikawa M, Takei K, Myagmar BE, Shinzato M, Machida N, Uezato H, Nonaka S and Kariya K: The Traf2- and Nck-interacting kinase as a putative effector of Rap2 to regulate actin cytoskeleton. J Biol Chem 279: 49488-49496, 2004
43. Nonaka H, Takei K, Umikawa M, Oshiro M, Kuninaka K, Bayarjargal M, Asato T, Yamashiro Y, Uechi Y, Endo S, et al: MINK is a Rap2 effector for phosphorylation of the postsynaptic scaffold protein TANC1. Biochem Biophys Res Commun 377: 573-578, 2008.

44. Machida N, Umikawa M, Takei K, Sakima N, Myagmar BE, Taira K, Uezato H, Ogawa Y and Kariya K: Mitogen-activated protein kinase kinase kinase kinase 4 as a putative effector of Rap2 to activate the c-Jun N-terminal kinase. J Biol Chem 279: 15711-15714, 2004

45. Wright JH, Wang X, Manning G, LaMere BJ, Le P, Zhu S, Khatry D, Flanagan PM, Buckley SD, Whyte DB, et al: The STE20 kinase HGK is broadly expressed in human tumor cells and can modulate cellular transformation, invasion, and adhesion. Mol Cell Biol 23: 2068-2082, 2003.

46. Collins CS, Hong J, Sapinoso L, Zhou Y, Liu Z, Micklash K, Schultz PG and Hampton GM: A small interfering RNA screen for modulators of tumor cell motility identifies MAP4K4 as a promigratory kinase. Proc Natl Acad Sci USA 103: 3775-3780, 2006.

47. Uechi Y, Bayarjargal M, Umikawa M, Oshiro M, Takei K, Yamashiro Y, Asato T, Endo S, Misaki R, Taguchi T and Kariya K: Rap2 function requires palmitoylation and recycling endosome localization. Biochem Biophys Res Commun 378: 732-737, 2009.

48. Raguz S, De Bella MT, Slade MJ, Higgins CF, Coombes RC and Yagüe E: Expression of RPIP9 (Rap2 interacting protein 9) is activated in breast carcinoma and correlates with a poor prognosis. Int J Cancer 117: 934-941, 2005.

49. Wang S, Zhang Z, Ying K, Chen JZ, Meng XF, Yang QS, Xie Y and Mao YM: Cloning, expression, and genomic structure of a novel human Rap2 interacting gene (RPIP9). Biochem Genet 41: $13-25,2003$.

50. Okamura SM, Oki-Idouchi CE and Lorenzo PS: The exchange factor and diacylglycerol receptor RasGRP3 interacts with dynein light chain 1 through its $\mathrm{C}$-terminal domain. J Biol Chem 281: 36132-36139, 2006.

51. Nomura K, Kanemura H, Satoh T and Kataoka T: Identification of a novel domain of Ras and Rap1 that directs their differential subcellular localizations. J Biol Chem 279: 22664-22673, 2004.

52. Vousden KH and Prives C: Blinded by the light: The growing complexity of p53. Cell 137: 413-431, 2009.

53. Rozan LM and El-Deiry WS: p53 downstream target genes and tumor suppression: A classical view in evolution. Cell Death Differ 14: 3-9, 2007.

54. Kruse JP and Gu W: Modes of p53 regulation. Cell 137: 609-622, 2009.

55. Fischer TH, Gatling MN, Lacal JC and White GC II: rap1B, a cAMP-dependent protein kinase substrate, associates with the platelet cytoskeleton. J Biol Chem 265: 19405-19408, 1990.

56. Torti M, Ramaschi G, Sinigaglia F, Lapetina EG and Balduini C: Association of the low molecular weight GTP-binding protein rap2B with the cytoskeleton during platelet aggregation. Proc Natl Acad Sci USA 90: 7553-7557, 1993.

57. Meyer D and Girma JP: von Willebrand factor: Structure and function. Thromb Haemost 70: 99-104, 1993.

58. Clemetson KJ: Platelet GPIb-V-IX complex. Thromb Haemost 78 : 266-270, 1997.

59. Torti M, Bertoni A, Canobbio I, Sinigaglia F, Lapetina EG and Balduini C: Rap1B and Rap2B translocation to the cytoskeleton by von Willebrand factor involves FcgammaII receptor-mediated protein tyrosine phosphorylation. J Biol Chem 274: 13690-13697, 1999.

60. Rosado JA and Sage SO: Farnesylcysteine analogues inhibit store-regulated $\mathrm{Ca}^{2+}$ entry in human platelets: Evidence for involvement of small GTP-binding proteins and actin cytoskeleton. Biochem J 347: 183-192, 2000.

61. Pike LJ: Lipid rafts: Heterogeneity on the high seas. Biochem J 378: 281-292, 2004.

62. Gousset K, Wolkers WF, Tsvetkova NM, Oliver AE, Field CL, Walker NJ, Crowe JH and Tablin F: Evidence for a physiological role for membrane rafts in human platelets. J Cell Physiol 190: 117-128, 2002.

63. Bodin $S$, Tronchère $H$ and Payrastre $B$ : Lipid rafts are critical membrane domains in blood platelet activation processes. Biochim Biophys Acta 1610: 247-257, 2003.

64. Torti M, Ramaschi G, Sinigaglia F, Lapetina EG and Balduini C: Glycoprotein IIb-IIIa and the translocation of Rap2B to the platelet cytoskeleton. Proc Natl Acad Sci USA 91: 4239-4243, 1994. 
65. Drin G and Scarlata S: Stimulation of phospholipase Cbeta by membrane interactions, interdomain movement, and $\mathrm{G}$ protein binding - how many ways can you activate an enzyme? Cell Signal 19: 1383-1392, 2007.

66. Hicks SN, Jezyk MR, Gershburg S, Seifert JP, Harden TK and Sondek J: General and versatile autoinhibition of PLC isozymes. Mol Cell 31: 383-394, 2008.

67. EhrlichLS, Medina GN and CarterCA: ESCRT machinery potentiates HIV-1 utilization of the PI(4,5)P(2)-PLC-IP3R-Ca(2+) signaling cascade. J Mol Biol 413: 347-358, 2011.

68. Schmidt M, Evellin S, Weernink PA, von Dorp F, Rehmann H, Lomasney JW and Jakobs KH: A new phospholipase-C-calcium signalling pathway mediated by cyclic AMP and a Rap GTPase. Nat Cell Biol 3: 1020-1024, 2001

69. Kelley GG, Reks SE and Smrcka AV: Hormonal regulation of phospholipase Cepsilon through distinct and overlapping pathways involving G12 and Ras family G-proteins. Biochem J 378: 129-139, 2004

70. Seifert JP, Zhou Y, Hicks SN, Sondek J and Harden TK: Dual activation of phospholipase C-epsilon by Rho and Ras GTPases. J Biol Chem 283: 29690-29698, 2008.

71.Wing MR, Bourdon DM and Harden TK: PLC-epsilon: A shared effector protein in Ras-, Rho-, and G alpha beta gamma-mediated signaling. Mol Interv 3: 273-280, 2003.

72. Jin TG, Satoh T, Liao Y, Song C, Gao X, Kariya K, Hu CD and Kataoka T: Role of the CDC25 homology domain of phospholipase Cepsilon in amplification of Rap1-dependent signaling. J Biol Chem 276: 30301-30307, 2001.

73. Song C, Satoh T, Edamatsu H, Wu D, Tadano M, Gao X and Kataoka T: Differential roles of Ras and Rapl in growth factor-dependent activation of phospholipase C epsilon. Oncogene 21: 8105-8113, 2002.

74. Wing MR, Snyder JT, Sondek J and Harden TK: Direct activation of phospholipase C-epsilon by Rho. J Biol Chem 278 41253-41258, 2003

75. Stope MB, Vom Dorp F, Szatkowski D, Böhm A, Keiper M, Nolte J, Oude Weernink PA, Rosskopf D, Evellin S, Jakobs KH and Schmidt M: Rap2B-dependent stimulation of phospholipase $\mathrm{C}$-epsilon by epidermal growth factor receptor mediated by c-Src phosphorylation of RasGRP3. Mol Cell Biol 24: 4664-4676, 2004.

76. Evellin S, Nolte J, Tysack K, vom Dorp F, Thiel M, Weernink PA, Jakobs KH, Webb EJ,Lomasney JW and Schmidt M: Stimulation of phospholipase C-epsilon by the M3 muscarinic acetylcholine receptor mediated by cyclic AMP and the GTPase Rap2B. J Biol Chem 277: 16805-16813, 2002.

77. Ivins JK, Yurchenco PD and Lander AD: Regulation of neurite outgrowth by integrin activation. J Neurosci 20: 6551-6560, 2000

78. Jeong HW, Nam JO and Kim IS: The COOH-terminal end of R-Ras alters the motility and morphology of breast epithelial cells through Rho/Rho-kinase. Cancer Res 65: 507-515, 2005.

79. Keely PJ, Rusyn EV, Cox AD and Parise LV: R-Ras signals through specific integrin alpha cytoplasmic domains to promote migration and invasion of breast epithelial cells. J Cell Biol 145 1077-1088, 1999.

80. Kwong L, Wozniak MA, Collins AS, Wilson SD and Keely PJ: R-Ras promotes focal adhesion formation through focal adhesion kinase and p130(Cas) by a novel mechanism that differs from integrins. Mol Cell Biol 23: 933-949, 2003.

81. Self AJ, Caron E, Paterson HF and Hall A: Analysis of R-Ras signalling pathways. J Cell Sci 114: 1357-1366, 2001.

82. Sethi T, Ginsberg MH, Downward J and Hughes PE: The small GTP-binding protein R-Ras can influence integrin activation by antagonizing a Ras/Raf-initiated integrin suppression pathway. Mol Biol Cell 10: 1799-1809, 1999.

83. Wozniak MA, Kwong L, Chodniewicz D, Klemke RL and Keely PJ: R-Ras controls membrane protrusion and cell migration through the spatial regulation of Rac and Rho. Mol Biol Cell 16 84-96, 2005

84. Schroder K, Hertzog PJ, Ravasi $\mathrm{T}$ and Hume DA: Interferon-gamma: An overview of signals, mechanisms and functions. J Leukoc Biol 75: 163-189, 2004.

85.Gollob JA, Sciambi CJ, Huang Z and Dressman HK: Gene expression changes and signaling events associated with the direct antimelanoma effect of IFN-gamma. Cancer Res 65: 8869-8877, 2005.
86. Avery-Kiejda KA, Bowden NA, Croft AJ, Scurr LL, Kairupan CF, Ashton KA, Talseth-Palmer BA, Rizos H, Zhang XD, Scott RJ and Hersey P: P53 in human melanoma fails to regulate target genes associated with apoptosis and the cell cycle and may contribute to proliferation. BMC Cancer 11: 203, 2011.

87. Fu G, Liu Y, Yuan J, Zheng H, Shi T, Lei W, Xiao T, Gao Y and Cheng S: Identification and functional analysis of a novel candidate oncogene RAP2B in lung cancer. Zhongguo Fei Ai Za Zhi 12: 273-276, 2009 (In Chinese).

88. Liu Y, Sun W, Zhang K, Zheng H, Ma Y, Lin D, Zhang X, Feng L, Lei $\mathrm{W}$, Zhang Z, et al: Identification of genes differentially expressed in human primary lung squamous cell carcinoma. Lung Cancer 56: 307-317, 2007.

89. Tang X, Mo C, Wang Y, Wei D and Xiao H: Anti-tumour strategies aiming to target tumour-associated macrophages. Immunology 138: 93-104, 2013.

90. Boffetta P, Winn DM, Ioannidis JP, Thomas DC, Little J, Smith GD, Cogliano VJ, Hecht SS, Seminara D, Vineis P and Khoury MJ: Recommendations and proposed guidelines for assessing the cumulative evidence on joint effects of genes and environments on cancer occurrence in humans. Int J Epidemiol 41: 686-704, 2012.

91. Lee EY and Muller WJ: Oncogenes and tumor suppressor genes. Cold Spring Harb Perspect Biol 2: a003236, 2010

92. Tsygankova OM, Wang H and Meinkoth JL: Tumor cell migration and invasion are enhanced by depletion of Rap1 GTPase-activating protein (Rap1GAP). J Biol Chem 288 24636-24646, 2013

93. Pannekoek WJ, Linnemann JR, Brouwer PM, Bos JL and Rehmann H: Rap1 and Rap2 antagonistically control endothelial barrier resistance. PLoS One 8: e57903, 2013.

94. Borland G, Smith BO and Yarwood SJ: EPAC proteins transduce diverse cellular actions of cAMP. Br J Pharmacol 158: 70-86, 2009.

95. Kennedy NJ, Sluss HK, Jones SN, Bar-Sagi D, Flavell RA and Davis RJ: Suppression of Ras-stimulated transformation by the JNK signal transduction pathway. Genes Dev 17: 629-637, 2003.

96. Potapova O, Gorospe M, Bost F, Dean NM, Gaarde WA Mercola D and Holbrook NJ: c-Jun N-terminal kinase is essential for growth of human T98G glioblastoma cells. J Biol Chem 275: 24767-24775, 2000.

97. Bost F, McKay R, Bost M, Potapova O, Dean NM and Mercola D: The Jun kinase 2 isoform is preferentially required for epidermal growth factor-induced transformation of human A549 lung carcinoma cells. Mol Cell Biol 19: 1938-1949, 1999.

98. Davis RJ: Signal transduction by the JNK group of MAP kinases. Cell 103: 239-252, 2000.

99. Margaritopoulos GA, Tsitoura E, Tzanakis N, Spandidos DA, Siafakas NM, Sourvinos G and Antoniou KM: Self-eating: Friend or foe? The emerging role of autophagy in idiopathic pulmonary fibrosis. BioMed Res Int 2013: 420497, 2013.

100. Haspel JA and Choi AM: Autophagy: A core cellular process with emerging links to pulmonary disease. Am J Respir Crit Care Med 184: 1237-1246, 2011.

101.Jarry TM, Memmi G and Cheung AL: The expression of alpha-haemolysin is required for Staphylococcus aureus phagosomal escape after internalization in CFT-1 cells. Cell Microbiol 10: 1801-1814, 2008.

102. Mestre MB, Fader CM, Sola C and Colombo MI: Alpha-hemolysin is required for the activation of the autophagic pathway in Staphylococcus aureus-infected cells. Autophagy 6 : $110-125,2010$

103. Mestre MB and Colombo MI: Staphylococcus aureus promotes autophagy by decreasing intracellular cAMP levels. Autophagy 8: 1865-1867, 2012

104. McLeod SJ, Shum AJ, Lee RL, Takei F and Gold MR: The Rap GTPases regulate integrin-mediated adhesion, cell spreading, actin polymerization, and Pyk2 tyrosine phosphorylation in B lymphocytes. J Biol Chem 279: 12009-12019, 2004.

105. Di JH, Qu DB, Lu Z, Li LT, Cheng Q, Xin Y, Zhang LZ, Zhang Y and Zheng JN: Rap2B promotes migration and invasion of human suprarenal epithelioma. Tumour Biol 35: 9387-9394, 2014. 